\title{
Crónica Comunitaria: \\ Actualidad institucional y económica de España en el marco de la Unión Europea (junio de 2017)
}

\author{
Communitarian Chronicle: \\ Spanish up-to-date institutional and economic framework \\ within the European Union (June 2017) \\ Beatriz Iñarritu \\ Profesora de la «Deusto Business School», Universidad de Deusto
}

doi: http://dx.doi.org/10.18543/ced-57-2017pp285-304

Sumario: I. Introducción.-II. El Estado de la Integración.III. Cuestiones generales de la actualidad económica.

\section{Introducción}

Durante el primer semestre de 2017, la Comisión Europea ha publicado diferentes informes relevantes a modo de reflexión sobre el futuro de la Unión Europea, incluyendo una propuesta sobre los derechos sociales y otra sobre el futuro de la Unión Monetaria.

La Unión ha celebrado su 60 aniversario a la vez que ha recibido formalmente la solicitud de salida del Reino Unido, y ciertamente los primeros movimientos en las negociaciones del Brexit no nos hacen pensar que vaya a resultar ser un proceso fácil.

El Semestre Europeo de 2017 siguió su curso, y respecto a las Recomendaciones Específicas que la Comisión dirigió a España destaca esta vez la crítica sobre la gestión de la corrupción y sobre la excesiva temporalidad en el empleo.

Y sin duda es preciso destacar la primera operación del Mecanismo Europeo de Resolución, que llevó a la venta del Banco Popular al Banco Santander, ante la crítica situación de falta de liquidez del primero. Aunque las autoridades comunitarias y nacionales se mostraron satisfechas por la decisión ya que no suponía coste alguno para el contribuyente, también hubo críticas y dudas respecto al proceso que había llevado a dicha situación y 
sobre el hecho de que unos 300.000 accionistas hayan perdido toda su inversión en el banco.

During the first six months of 2017, the European Commission has published different reports in order to make proposals for the reflection about the European Union's future, including a report on the social rights and another one about the future of the Monetary Union.

The EU has celebrated its $60^{\text {th }}$ anniversary and at the same time it has officially received the United Kingdom's application to leave and certainly the first movements in this Brexit negotiations do not make us think that it is going to be an easy process.

The 2017 European Semester went on and referring to the Specific Recommendations addressed to Spain, it was particularly outstanding the criticism to the management of corruption and to the excessive temporary work.

And of course it is necessary to outline the first deal of the Single Resolution Mechanism, that resulted in the sale of Banco Popular to Banco Santander, as the consequence of the critical situation of liquidity of the first one. Although both European and national authorities felt satisfied about the decision, as it did not represent any cost for the taxpayer, many criticisms and doubts arose referring to the process that had led to that situation and because around 300000 shareholders have lost all their investment in the bank.

\section{El estado de la integración}

1. Presentación del «Libro blanco sobre el futuro de la UE» y celebración del 60. ${ }^{\circ}$ aniversario del Tratado de Roma

A comienzos de marzo, el presidente de la Comisión Europea, Jean Claude Juncker, presentó su «Libro Blanco sobre el futuro de la Unión Europea» que fue interpretado por una mayoría de analistas como un inusual ejercicio de autocrítica sobre su papel en la crisis del último decenio.

«La Unión ha estado por debajo de las expectativas en la peor crisis financiera, económica y social de la posguerra», resumía el texto.

«La recuperación está mal distribuida entre la sociedad y las regiones. Solucionar el legado de la crisis, desde el desempleo de larga duración hasta los altos niveles de deuda, sigue siendo una prioridad urgente», apuntaba Bruselas en el documento.

En este mismo tono, añadía que «los acontecimientos han alimentado las dudas acerca de la economía social de mercado y su capacidad para con- 
seguir que cada generación esté mejor que las anteriores»; es así como concluía que «por primera vez desde la Segunda Guerra Mundial hay un riesgo real de que los jóvenes vivan peor que sus padres».

La Comisión destacaba en el análisis los logros de la construcción europea. «La UE es el mayor mercado común del mundo, el euro es la segunda moneda más usada, la diplomacia europea ha liderado el reciente acuerdo nuclear con Irán, o el del clima en París». Pero añadía la advertencia de que «el papel de Europa en el mundo se reduce, tanto en población como en riqueza o en un concepto mucho más líquido como es el atractivo internacional».

En este desolador diagnóstico, Bruselas señala que Europa «no puede ser naíf; ser un poder blando ya no es suficiente para ser realmente poderoso cuando la fuerza puede prevalecer sobre las reglas», en lo que se interpretó como una referencia directa a la invasión rusa de Ucrania o a las invectivas de Trump.

Bruselas abandonaba su tradicional complacencia y lanzaba una queja directa contra los Estados miembros que, con frecuencia, «culpan a Bruselas de los problemas y nacionalizan los éxitos».

Ante la Eurocámara, Juncker señaló que «cualquier día triste de 2017 seguirá siendo mucho más alegre que el de nuestros antepasados en los campos de batalla».

Y mostró en el documento hasta cinco escenarios de futuro de la UE en el horizonte de 2025, dependiendo del camino que decida tomar la Unión:

1. «Seguir igual». Se trataría de aplicar la agenda actual, con pasos adelante en los asuntos de seguridad y defensa. El propio Ejecutivo comunitario admite que la integridad de la UE podría verse en entredicho, pero esta vía permitiría «acabar con el reflejo de regularlo absolutamente todo», señalaba Juncker.

2. «Solo el Mercado Único». Es la opción más minimalista. Se basaría en preservar las cuatro grandes libertades, y convertiría el mercado común en la única razón de ser de la UE, eliminando competencias en todo lo demás. «No es mi opción, pero hay Gobiernos que quieren limitar el papel de la Comisión», apuntó el presidente.

3. «Los que desean hacer más, hacen más». La UE a 27 seguiría funcionando como hasta ahora, pero se incentivarían las diferentes velocidades en las agendas fundamentales, para evitar que los vetos impidan avanzar a quienes quieran hacerlo. Europa ya ha empezado a dar pasos por esta vía de «coaliciones de voluntades». La Comisión destaca que este camino permitiría avan- 
zar en materias de defensa, seguridad interior y asuntos sociales, pero admite también podría generar problemas de legitimidad democrática.

4. «Hacer menos pero de forma más eficiente». Bruselas plantea la posibilidad de que la UE se centre en unas áreas de actuación prioritarias. Cita como ejemplos que, por esta vía, en 2025 la UE contaría con una Autoridad Europea de Telecomunicaciones con facultades para liberar frecuencias para servicios de comunicaciones transfronterizos o para proteger los derechos de los usuarios de redes móviles e internet en cualquier lugar de la UE, y también podría contar con una Agencia Europea de Lucha contra el Terrorismo. Junto con el escenario anterior es, para la Comisión, el escenario más realista.

5. «Hacer mucho más conjuntamente». Se trataría de que los Estados miembros decidieran compartir más competencias, recursos y tomas de decisiones en todos los ámbitos. Por este camino, la Unión avanzaría hacia una mayor armonización fiscal, social y financiera, y permitiría poner en marcha estímulos contra los shocks económicos y haría posible la creación de una Unión Europea de la Defensa. Es el salto federal que soñaron los padres fundadores de la UE, pero que, en efecto, no parece factible para la propia Comisión. Bruselas admite el riesgo de «perder la confianza de parte de la sociedad que cree que la UE carece de legitimidad o se ha hecho con demasiado poder».

En su discurso sobre el Estado de la Unión de septiembre de 2017 Juncker presentará el posicionamiento de la institución que preside respecto a estos planteamientos de futuro, antes de que los líderes de los Estados miembros acuerden las primeras conclusiones en el Consejo Europeo de diciembre.

Y apenas unos días después de la presentación de este «Libro Blanco sobre el futuro de la UE», el 25 de marzo, la UE celebró el $60 .^{\circ}$ aniversario de la firma del Tratado de Roma que, en 1957, creó la Comunidad Económica Europea.

Los actos programados para dicha celebración también tuvieron lugar en la capital italiana y se desarrollaron en un clima agridulce, ya que no son pocos los motivos para el desánimo en Europa, motivos como la crisis económica, la gestión de la crisis de los refugiados, el Brexit, o el auge de los populismos.

Uno de los actos más relevantes de la celebración tuvo lugar en el Vaticano. El Papa Francisco dirigió unas palabras a los jefes de Estado y de Gobierno de Veintisiete países de la UE (no estaba invitada la premier bri- 
tánica), con las que denunció los graves problemas que atraviesa Europa, y pidió a los líderes europeos que recuperen la idea que propició el inicio de la construcción comunitaria, la solidaridad, a la que definió como «el mejor antídoto contra los modernos populismos», y les urgió a que la materialicen con «hechos y gestos concretos».

Como conclusión de esta celebración, los líderes de 27 países de la Unión Europea firmaron la «Declaración de Roma», que subraya la unidad e indivisibilidad de los Estados miembros y la voluntad de seguir avanzando en el proyecto europeo.

«La unidad es una necesidad y nuestra libre elección» señalaba el texto. «Actuaremos juntos, a distintos ritmos y con distinta intensidad cuando sea necesario, mientras avanzamos en la misma dirección, como hemos hecho en el pasado, de conformidad con los Tratados y manteniendo la puerta abierta a quienes quieran unirse más adelante, añadía.

\section{Comisión Europea: Propuestas sobre un Pilar Europeo de Derechos Sociales» y sobre el futuro de la Unión Monetaria}

La Comisión Europea presentó dos importantes propuestas en este primer semestre de 2017.

A finales de abril hizo pública su propuesta sobre el «Pilar Europeo de los Derechos Sociales», que establece una serie de principios y derechos esenciales que respalden unos mercados de trabajo y unos sistemas de protección social justos y que funcionen correctamente.

Conjuntamente, estos principios y derechos establecen una agenda ambiciosa para conseguir un mejor funcionamiento de las Economías, y para conseguir también que las sociedades sean más equitativas y tengan una mayor capacidad de adaptación. El objetivo es promover un proceso de convergencia hacia unas mejores condiciones de vida y de trabajo en toda Europa, con la aspiración de proporcionar derechos nuevos y más efectivos a los ciudadanos, que permitan hacer frente a los nuevos retos sociales y laborales, incluyendo los cambios provocados por las nuevas tecnologías y la revolución digital.

Estos principios y derechos se estructuran en tres grandes categorías. Igualdad de oportunidades y acceso al mercado de trabajo, Condiciones equitativas de trabajo y Protección e inclusión sociales. 


\section{PILAR EUROPEO DE DERECHOS SOCIALES}

\section{Igualdad de oportunidades y acceso al mercado de trabajo}

- Educación, formación y aprendizaje permanente.

- Igualdad de género.

- Igualdad de oportunidades.

- Apoyo activo para el empleo.

\section{Condiciones equitativas de trabajo}

- Empleo seguro y adaptable.

- Salarios.

- Información sobre las condiciones de trabajo y la protección en caso de despido.

- Diálogo social y participación de los trabajadores.

- Equilibrio entre vida profesional y vida privada.

- Entorno de trabajo saludable, seguro y adaptado y protección de datos.

\section{Protección e inclusión sociales}

- Asistencia y apoyo a los niños.

- Protección social.

- Prestaciones por desempleo.

- Renta mínima.

- Pensiones y prestaciones de vejez.

- Sanidad.

- Inclusión de las personas con discapacidad.

- Cuidados de larga duración.

- Vivienda y asistencia para las personas sin hogar.

- Acceso a los servicios esenciales.

Bruselas decidía, de esta forma, rescatar su Agenda Social con la que pretende contrarrestar las numerosas críticas recibidas por su excesivo perfil liberal y poco combativo con la desigualdad, la pobreza y los asuntos sociales.

Y como inicio de la puesta en marcha de este «Pilar Social», la Comisión presentó también una batería de propuestas normativas, entre las que destaca una Directiva sobre conciliación de la vida laboral y familiar que incluye las propuestas de un permiso retribuido para cada progenitor de, al menos, cuatro meses y que podría ser solicitado hasta que los niños cumplan 12 años, el establecimiento de un mínimo de 10 días de permiso de paternidad (en el caso de España ya es de un mes, pero hay países donde no está garantizado) y otro mínimo de cinco días anuales retribuidos para atender a los familiares dependientes que estén seriamente enfermos. 
Y el 31 de mayo Bruselas presentó el esperado documento de reflexión sobre la profundización de la Unión Económica y Monetaria, en el que propone nuevas iniciativas de aquí a 2025 para mejorar el funcionamiento de la Eurozona.

«El euro está lejos de ser perfecto y necesita reformas», justificaba el texto de la Comisión. «La convergencia económica de los primeros años del euro fue ilusoria y en la actualidad la eurozona está partida en dos, por lo que es preciso dar pasos para terminar con la actual polarización», añadía.

El vicepresidente de la institución, Valdis Dombrovskis, fue el encargado de presentar estas propuestas que incluyen, en última instancia la aprobación de un presupuesto único para la Eurozona y la creación de un Tesoro europeo con poderes para emitir Deuda común.

En todo caso, a más corto plazo, la Comisión propone crear un nuevo instrumento financiero, denominado «Sovereign Bond Backed Securities», que permita empaquetar deuda de distintos países del euro aunque sin compartir necesariamente el riesgo.

Este «activo seguro europeo» sería un bono denominado en euros pero con una mutualización de deuda total, parcial o nula, y que podría llegar a convertirse en referencia para los mercados financieros europeos una vez que tuviera una circulación suficiente.

Y para el más largo plazo, en el horizonte de 2025, Bruselas presenta sus propuestas más ambiciosas como son el presupuesto común de la Eurozona, que ejerza «una función de estabilización macroeconómica», y la creación de un Tesoro con capacidad para emitir Deuda común, los llamados Eurobonos, con algún grado de mutualización del riesgo y con capacidad también para gestionar el presupuesto común.

Bruselas pretende también apuntalar la gobernanza económica común con una presidencia permanente del Eurogrupo, presidencia que podría ser compatible con el papel de comisario de Asuntos Económicos. Se trataría de crear la figura de un superministro de Finanzas del euro que, en todo caso, debería rendir cuentas a la Eurocámara. Y también plantea convertir el Mecanismo Europeo de Estabilidad (MEDE) en un auténtico Fondo Monetario Europeo capaz de asistir a países en dificultades.

La Comisión defiende, por tanto, la emisión conjunta de deuda pública como medida necesaria para reforzar la integración, aunque, con ciertas concesiones hacia los países que más se oponen a este proyecto (Alemania), al prever la posible modificación a largo plazo de la normativa que otorga a la deuda pública el estatus de activo 100\% seguro. 


\section{Brexit: activación del proceso y primeras reuniones de la negociación}

El pasado 29 de marzo, el embajador británico ante la UE, Tim Barrow entregó al presidente del Consejo Europeo Donald Tusk la carta con la que notificó la intención del Reino Unido de abandonar la Unión. Comenzaba así el proceso de negociación que culminará con la primera salida de un Estado Miembro de la UE. Nueve meses después de la celebración del referéndum, el Reino Unido iniciaba el fin de casi cuarenta y cinco años de historia en común.

Tras dos días de debate, la Cámara de los Comunes había votado el 1 de febrero, on 498 votos a favor y 114 en contra, la autorización para que la primera ministra británica, Theresa May, activara el proceso de salida de la UE. Londres superaba así el primer paso del escrutinio parlamentario al que le obligó el Tribunal Supremo.

El resultado de la votación abría, sin embargo, una nueva crisis en la oposición laborista, ya que 47 de sus 229 diputados votaron en contra de la autorización, desafiando al líder de la formación, Jeremy Corbyn.

A los díscolos laboristas se sumaron los 54 legisladores del nacionalismo escocés, 8 de los nueve liberal-demócratas y otros pocos procedentes de partidos minoritarios, con lo que la suma del rechazo al inicio del Brexit llegó a los 114 diputados mencionados, casi una sexta parte de la Cámara. Entre ellos destacó particularmente el voto de un diputado tory, el veterano Ken Clarke, ex canciller de Finanzas con Thatcher y europeísta convencido, quien pronunció un emotivo discurso ante la Cámara.

«Creo que nuestra pertenencia a la UE restauró nuestra confianza y nos dio un rol político en el mundo, como un líder en la Unión, lo que nos dio más valor ante nuestros aliados, como los Estados Unidos, e hizo que nuestro rivales, como Rusia, nos tomaran con más seriedad. Ayudó también a reforzar nuestros propios valores. Nuestra economía se benefició enormemente y continuó beneficiándose mucho más, a medida que se desarrolló el mercado, por nuestra estrecha y exitosa implicación en el desarrollo de relaciones comerciales con los habitantes del continente», señaló Clarke.

En su argumentación destacó asimismo que hubo varias cuestiones que no se trataron en el referéndum, incluidos el mercado único y la unión aduanera y, en este sentido, afirmó que «es absurdo decir que todos los electores conocían las diferencias entre la unión aduanera y el mercado único, y que contaban con un punto de vista estudiado de las bases de nuestra futura relación comercial con Europa». «Me parece evidente que si creamos nuevos aranceles, nuevas barreras reguladoras, certificados de origen y todo lo demás entre nosotros y el mayor mercado libre del mundo, debilitaremos nuestra posición económica con respecto a la que podría haber sido en el futuro. Por eso es importante tratar este asunto en particular», señaló. 
«Me dicen que soy pesimista y que vamos a combinar la retirada del mercado único y de la unión aduanera con un gran y nuevo futuro globalizado que nos presenta tremendas oportunidades. Parece ser que, cuando sigamos al conejo por el agujero, emergeremos en un país de las maravillas donde, súbitamente, países de todo el mundo harán cola para darnos ventajas comerciales y acceso a sus mercados que nunca logramos como miembros de la UE. Hombres simpáticos como el presidente Trump y el presidente Erdogan se sienten ya impacientes para abandonar su proteccionismo y darnos acceso. No quiero ser muy cínico. Espero que sea cierto. Quiero el mejor resultado para Reino Unido en este proceso. Sin duda, en algún lugar, un sombrerero está sirviendo té a sus invitados con un lirón en la tetera» señaló a modo de conclusión.

También George Osborne, ex ministro de Economía y hombre fuerte del Gobierno de David Cameron, dio voz al sentir de muchos diputados conservadores. Tras haber defendido con pasión la permanencia, advirtió de que si el Parlamento votaba contra la activación del artículo 50 del Tratado de la UE, se desataría una «profunda crisis constitucional» al rechazar la voluntad popular dictada en el referéndum de junio de 2016. Pero, por otra parte también criticó que el Gobierno de May hubiera decidido «no convertir en prioridad a la economía» sino priorizar el control de la inmigración.

Una semana después, el 8 de febrero, la misma Cámara de los Comunes dio la luz verde definitiva al proyecto de ley de activación del Brexit, con un margen de 494 votos favorables sobre 122 votos en contra, algo menor que el mostrado por los diputados británicos la semana anterior.

La aprobación final no llegó a incluir la enmienda que hubiera exigido que el gobierno garantizase unilateralmente los derechos de los ciudadanos de otros países europeos residentes en Reino Unido.

La única concesión de May fue la aceptación de que el voto en ambas Cámaras del Parlamento británico, sobre el acuerdo que se alcance finalmente con los 27 al final del periodo de dos años de negociaciones previsto, se produzca antes de que la votación del Parlamento Europeo.

El gobierno de May trasladaba así la presión a los diputados puesto que habrá voto en el Parlamento británico, pero será del tipo «lo tomas o lo dejas». Si el Parlamento rechaza el acuerdo, el gobierno no estará obligado a volver a la mesa de negociación. Reino Unido simplemente saldría de la UE sin un acuerdo, es decir, sin un nuevo marco que regule sus relaciones con el bloque, y los diputados serían los responsables de que el Brexit se convirtiera en un salto sin red.

Al recibir la carta británica el 29 de marzo, el presidente del Consejo Europeo Donald Tusk afirmaba que «no hay razón para fingir que hoy es un día feliz, ni en Bruselas, ni en Londres». 
Ese mismo día, los Veintisiete hicieron pública una declaración conjunta en la que dejaban claro que en el inicio de las negociaciones su intención es pactar las líneas maestras del proceso. «Empezaremos centrándonos en los acuerdos clave para una salida ordenada», advertía el comunicado.

Esta afirmación significaba que antes de empezar a hablar de acuerdos comerciales post-Brexit, la UE pretende que el Reino Unido se comprometa a saldar sus cuentas pendientes con el presupuesto comunitario (unos 60.000 millones de euros según los primeros cálculos de la Comisión, sobre partidas presupuestarias ya acordadas, derechos de pensión de los funcionarios europeos de nacionalidad británica y préstamos otorgados en nombre de la UE) y acordar los derechos de los ciudadanos de ambos territorios que viven en el otro. Era la respuesta a la petición de Londres de simultanear en paralelo el acuerdo de salida de la Unión y el acuerdo que defina la relación económica y comercial posterior entre Reino Unido y la UE.

El 29 de abril se celebró una cumbre extraordinaria de jefes de Estado y de Gobierno de los Veintisiete. A partir de este momento, la UE-27 ha comenzado a funcionar de manera paralela a la UE-28, de forma que Londres ya no participa ni en deliberaciones ni en decisiones del Consejo Europeo ni en los Consejos de ministros que le afecten.

Tras esta reunión, los líderes de los Veintisiete aprobaron, por unanimidad y tras apenas unos minutos de debate, las líneas maestras de la negociación con el Reino Unido. La UE-27 decidió endurecer su posición, planteando que, en efecto, el inicio de las conversaciones debería centrarse en los temas de la deuda que deben pagar los británicos y también en los derechos de los tres millones de ciudadanos de la UE que residen en la isla (y del millón y medio de británicos residentes en suelo continental). De esta forma, sólo cuando se produzcan suficientes avances en estos asuntos se negociará la futura relación comercial de Reino Unido y Europa.

Siguiendo estas directrices, la Comisión Europea publicó el 3 de mayo el mandato de negociación que, en efecto, priorizaba ambos asuntos.

El negociador jefe de la Comisión, Michel Barnier, compareció en rueda de prensa para explicar que los dos años previstos para negociar «pasarán rápido» y que «el camino es muy complejo». «Algunos han creado la ilusión de que el Brexit no tendrá impacto, que se puede negociar rápido. No es el caso», zanjó el excomisario francés.

En el documento se detallaba que el Reino Unido debería pagar por los proyectos comunitarios incluidos en el Presupuesto multianual actual, incluso si son aprobados una vez que se produzca la salida del pais de la UE. También debería cubrir «todos los gastos» asociados al traslado de las agencias europeas radicadas en Londres. Fuentes comunitarias informaron que estos costes incluirían la penalización por romper los 25 años de contrato por la sede de la Agencia Europea del Medicamento. Estas circunstan- 
cias podrían incrementar sustancialmente la factura que la Unión reclama a Londres.

Y sostenía también que todos los ciudadanos europeos que recalen en Reino Unido antes de la salida efectiva de la UE, previsiblemente el 30 de marzo de 2019, tendrían derechos adquiridos, que podrían invocar ante el Tribunal de Justicia de la UE.

\section{Nuevo presidente del Parlamento Europeo y reelección del presidente del Consejo Europeo}

En la sesión plenaria del Parlamento Europeo del 17 de enero, el italiano Antonio Tajani fue nombrado nuevo presidente del Parlamento Europeo, en sustitución del socialista alemán Martin Schulz.

El nuevo líder de la Eurocámara ha desarrollado casi toda su carrera política en Bruselas, donde llegó a ser vicepresidente de la Comisión Europea, primero como comisario responsable de la cartera de Transportes y, después, de la de Industria, entre 2008 y 2014.

Con este nombramiento, las tres grandes instituciones comunitarias (Comisión, Consejo y Parlamento) pasaban a estar controladas por el conservador Partido Popular Europeo.

Y en marzo se produjo la reelección del polaco Donald Tusk como presidente del Consejo Europeo, a pesar de la insólita oposición de su propio país.

El gobierno polaco, dirigido por el ultraconservador partido Ley y Justicia, tuvo que enfrentarse al respaldo unánime del resto de sus socios a la continuidad de Tusk en el cargo.

El Ejecutivo polaco no solo achacaba a Tusk una excesiva propensión a inmiscuirse en asuntos internos de Polonia sino que también lo consideraba «el candidato de Alemania».

\section{Cuestiones generales de la actualidad económica}

\section{El Semestre Europeo 2017: Informes-país y Recomendaciones Especificas}

Siguiendo la secuencia cronológica del «Semestre Europeo», la Comisión Europea publicó en febrero sus informes por país, que concluyeron que seis países, Francia, Italia, Portugal, Bulgaria, Chipre y Croacia, mostraban «desequilibrios macroeconómicos excesivos».

Bruselas destacaba en particular la situación de Francia, a pesar de las reformas emprendidas en el país y de los pasos «graduales» en la buena di- 
rección. Y muy cerca de Francia, la Comisión también señalaba a Italia, considerando que, en efecto, también la economía italiana experimentaba desequilibrios excesivos, centrados básicamente en una deuda pública superior al $130 \%$ del PIB.

En una situación relativamente mejor, Bruselas identificó a otro grupo de seis países, que también presentan Desequilibrios Macroeconómicos pero sin que éstos fueran considerados excesivos. En éste se encontraba España, de quien Bruselas destacaba el crecimiento económico como principal motor para reducir la deuda, pero alertando también de que siguen existiendo riesgos elevados de sostenibilidad presupuestaria a medio plazo. De igual manera, el informe señalaba que aunque la creación de empleo ha sido sólida en los últimos años y el desempleo ha disminuido rápidamente, éste sigue siendo muy elevado.

Y tras la presentación de los Programas de Estabilidad y Convergencia, así como de los preceptivos Programas Nacionales de Reforma por parte de los Estados miembros, la Comisión Europea presentó el 22 de mayo sus Recomendaciones Específicas por país (REP), en las que exponía sus orientaciones en materia de política económica dirigidas a cada Estado miembro para los 12 a 18 próximos meses.

En estos documentos Bruselas señalaba que, aunque la economía de la UE y de la zona del euro está demostrando su solidez, ésta continúa afrontando desafíos tales como el lento crecimiento de la productividad, las consecuencias de la crisis (incluida la persistencia de desigualdades) y la incertidumbre derivada fundamentalmente de factores externos. Esa es la razón por la que la Comisión pedía a los Estados miembros la aplicación de las prioridades económicas y sociales definidas de forma común a nivel europeo: fomento de la inversión, continuación de las reformas estructurales y garantía de la adopción de políticas presupuestarias responsables.

Por lo que se refiere a las Recomendaciones dirigidas a España, la Comisión hizo hincapié, entre otros, en los problemas siguientes:

- Corrupción: a pesar del incremento del número de investigaciones a escala local y autonómica, ni se han diseñado estrategias preventivas específicas en estos niveles de la Administración ni tampoco existe una estrategia preventiva compartida entre ellas. Y tampoco se ha realizado hasta ahora un seguimiento específico de otras deficiencias, como son la ausencia de legislación para proteger a los denunciantes, el grado de independencia de la recientemente creada Oficina de Conflictos de Intereses y la inexistencia de normas que regulen las actividades de los grupos de presión. Respecto a la excesiva duración de los procedimientos judiciales en los asuntos de corrupción, la Comisión señala que si bien en 2015 se modificó la Ley de 
Enjuiciamiento Criminal, esta medida podría conllevar impunidad en los asuntos complejos de corrupción puesto que los plazos fijados podrían ser insuficientes para instruir las causas.

- IVA: a pesar de contar con un tipo normal en consonancia con la media de la UE, los ingresos por este concepto son relativamente bajos en España, debido a la aplicación muy generalizada de exenciones o tipos reducidos. Del mismo modo, y a pesar de algunas medidas adoptadas en los últimos años principalmente en el sector de la energía, los ingresos procedentes de los impuestos medioambientales se sitúan entre los más bajos de la UE; la imposición de tributos sobre la contaminación y la utilización de los recursos podría generar mayores ingresos y aportar importantes beneficios sociales y medioambientales.

- Desempleo: el desempleo ha disminuido rápidamente, pero sigue siendo uno de los más elevados de la UE, en especial entre los jóvenes y las personas escasamente cualificadas, lo que conlleva riesgos de desvinculación del mercado de trabajo. España está adoptando medidas de apoyo a los jóvenes, pero su eficacia depende en parte del rendimiento de los Servicios Públicos autonómicos de empleo. Y Bruselas señala que hay margen para potenciar su cooperación con los Servicios Sociales y para mejorar la cooperación de los Servicios Públicos de empleo con los empresarios.

- Temporalidad del empleo: España presenta una de las tasas más elevadas de empleo temporal de la UE, y muchos de los contratos temporales son de muy corta duración; la utilización generalizada de este tipo de contratos va asociada a un menor crecimiento de la productividad, un empeoramiento de las condiciones de trabajo y un mayor riesgo de pobreza. Aunque las reformas introducidas recientemente han conseguido reducir ligeramente la segmentación entre los contratos indefinidos y los temporales y combatir el abuso de la contratación temporal, algunas de las características del mercado laboral español todavía pueden desincentivar la contratación indefinida; el sistema de incentivos a la contratación sigue siendo disperso y no se centra de forma efectiva en el fomento de la contratación indefinida.

Además, la Comisión también recomendó el cierre de los Procedimientos de Déficit Excesivo para Croacia y Portugal, de manera que, con esta decisión, solo quedarían cuatro Estados miembros sometidos al componente corrector del Pacto de Estabilidad y Crecimiento (Grecia, Francia, Reino Unido y España), lo que contrasta con los 24 Estados que se encontraban en esta situación en 2011. 
Y por lo que se refiere al procedimiento de Desequilibrios Macroeconómicos, la Comisión dictaminó que para tres de los seis países que en febrero habían sido incluidos en el grupo de «Desequilibrios Excesivos», Chipre, Italia y Portugal, ya no existían motivos analíticos para acelerar el procedimiento correspondiente, siempre que estos tres países «apliquen plenamente las reformas establecidas en sus recomendaciones específicas».

\section{European Semester 2017}

Situation under the Macroeconomic Imbalances Procedure and the Stability and Growth Pact

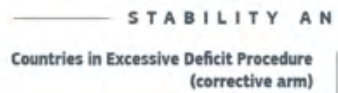

(corrective arm)

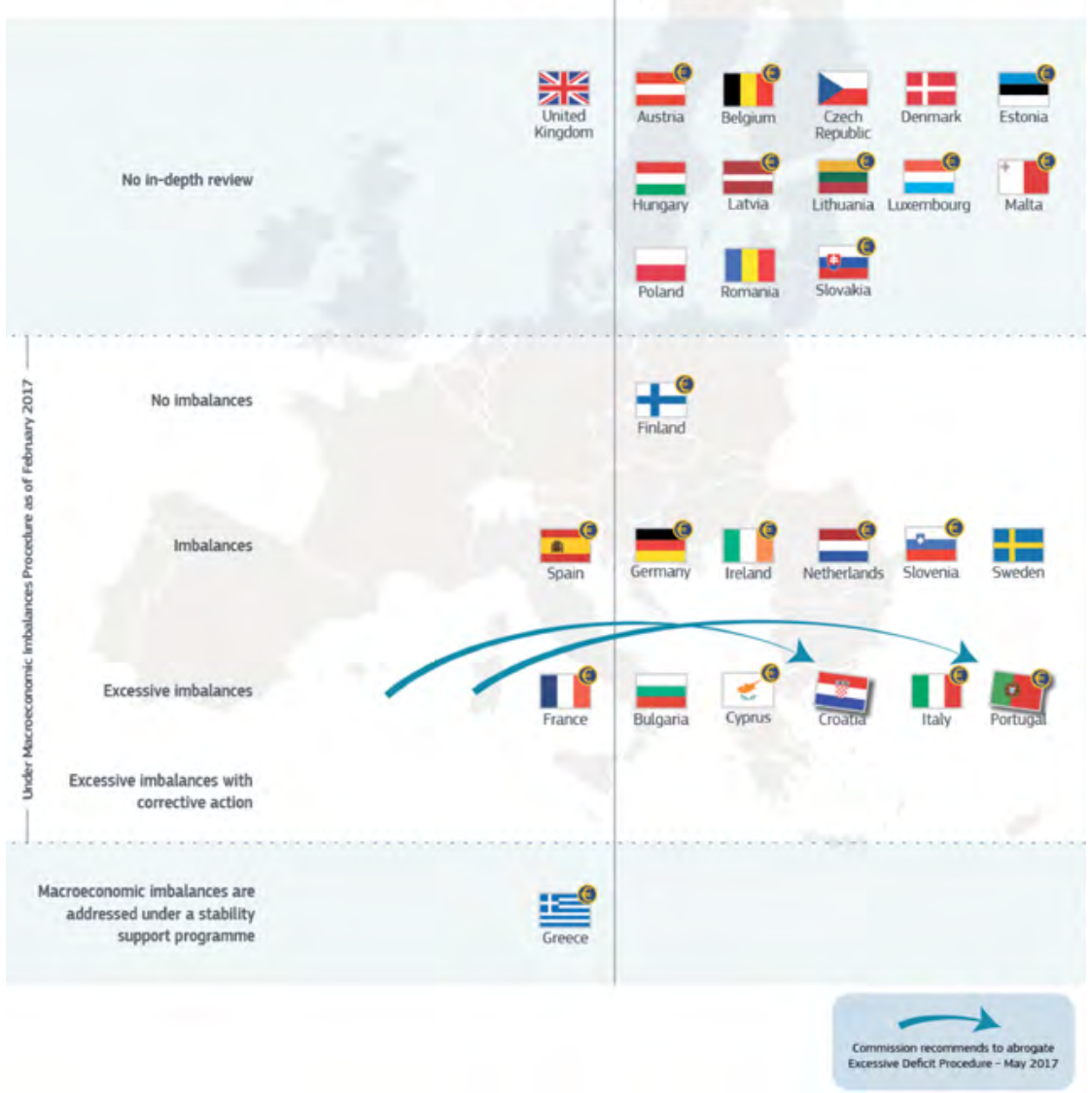

Fuente: Comisión Europea, mayo de 2017. 


\section{Unión Bancaria: Primera operación del Mecanismo Único de Resolución con el Banco Popular}

El pasado 7 de junio, se produjo la primera actuación del Mecanismo Único de Resolución (MUR), uno de los pilares de la Unión Bancaria.

El riesgo de colapso ante la posibilidad de que el Banco Popular no hubiera podido atender las retiradas de dinero de sus clientes llevó a las autoridades europeas a decidir, por vez primera, una intervención rápida e inédita de «resolución» de un banco europeo.

El Banco Central había determinado, en primera instancia, el 6 de junio, la necesidad de dicha intervención ante la delicada situación del sexto banco español. En su opinión, el Pastor estaba a punto de caer o era probable que cayese («failing or likely to fail», según señalaba el BCE literalmente en inglés), de acuerdo con las disposiciones contenidas en el Reglamento del MUR. «El deterioro significativo en su situación de liquidez en los días recientes incapacitaría al banco para hacer frente a sus deudas o compromisos a su vencimiento, en un futuro próximo», señalaba la nota de prensa del BCE.

Esta valoración sobre la falta de viabilidad del banco puso en marcha el Mecanismo de Resolución por vez primera en su corta existencia.

Y aunque, según explicó la presidenta de la Junta Única de Resolución («the Single Resolution Board», SRB, en inglés), Elke König, la operación estaba prevista para el fin de semana, «no dio tiempo, la situación de liquidez del banco se hizo insostenible y obligó a actuar con rapidez».

En apenas unas horas, la Junta, con la luz verde de la Comisión Europea, tomó la decisión de intervenir, encargando al Fondo de Reestructuración Ordenada Bancaria, el FROB español, la venta del Banco Popular, operación que finalmente se cerró con el Banco Santander, quien aceptó la compra del Popular por la simbólica cifra de un euro.

«Hoy, la Junta Única de Resolución ha transferido todas las acciones e instrumentos de capital del Banco Popular al Banco Santander. Esto significa que el Banco Popular operará en condiciones normales de negocio como miembro solvente y líquido del grupo Santander con efecto inmediato», señalaba la nota de prensa de la Junta.

La decisión de venta «se realizó por el interés público, puesto que protege a todos los depositantes del Banco Popular y asegura la estabilidad financiera», añadía la misma nota. En opinión de la presidenta König, la decisión demostraba que las herramientas otorgadas a las autoridades de resolución después de la crisis «son efectivas para proteger a los contribuyentes ante nuevos rescates bancarios».

El plan aprobado consistía en convertir la deuda subordinada (de peor calidad) en acciones para unirlas al resto de acciones del Popular y traspasar toda esta cartera al Banco Santander por un euro. 
La justificación dada por las autoridades europeas y nacionales coincidía en que, de esta manera, se «resolvía» un banco inviable, aplicando una quita total, del $100 \%$, a accionistas y bonistas, y se traspasándolo a un comprador sin ningún coste para el contribuyente. El ministro de Economía español, Luis de Guindos, declaró entonces que, en efecto, ésta había sido «una buena salida para la entidad, dada la situación a la que había llegado en las últimas semanas», y que la decisión de las autoridades europeas se había tomado «con total transparencia» y «sin la utilización de recursos públicos», lo que evitaba un eventual contagio al riesgo soberano, «como ocurrió en épocas pasadas».

Sin embargo, también se escucharon fuertes críticas en relación al proceso que había llevado al Popular a esta situación. El banco, muy lastrado por activos inmobiliarios, había superado todas las pruebas de estrés y exámenes de calidad de sus activos efectuados por el Mecanismo Único de Supervisión, la otra herramienta de la Unión Bancaria. Y las auditorías contables, realizadas por firmas cualificadas y reputadas, habían permitido diferentes ampliaciones de capital y emisiones de bonos convertibles.

Y la crítica fundamental se dirigió al perjuicio causado a unos 300.000 accionistas y poseedores de deuda de peor calidad del Banco que, de un día para otro, perdieron toda su inversión.

A esta cuestión se añadía el daño causado a los trabajadores del banco, ya que en una proporción estimada de tres de cada cuatro eran accionistas de la entidad, y porque su futuro laboral quedaba en el aire.

Y, por último, se planteó la cuestión del incremento y la concentración de cuota de negocio bancario en España en manos del Santander. La entidad resultante de la absorción será, en efecto, la mayor de las entidades bancarias españolas, en créditos y en depósitos, y llegará a contar con 17 millones de clientes.

\section{Tribunal de Justicia: sentencia contra los recargos en las llamadas telefónicas de los servicios post-venta}

En marzo el Tribunal de Justicia europeo declaró ilegales los números de teléfono con tarifas especiales que algunas compañías utilizan para su servicio post-venta.

Los jueces europeos aseguraron que esos recargos son incompatibles con la directiva europea de derechos del consumidor aprobada en 2011. Y en su veredicto exigían que todos estos servicios deben facturarse a precio de llamada normal, ya sea a un teléfono fijo o móvil.

La sentencia se deriva de una consulta prejudicial planteada por un tribunal alemán que debía decidir sobre el caso de una empresa de aparatos 
eléctricos y electrónicos que ofrecía a sus clientes un servicio telefónico con un prefijo que encarecía el coste de la llamada haciéndola más costosa respecto a una llamada estándar a un número alemán fijo o móvil.

La directiva europea de derechos del consumidor exige que, en caso de ofrecerse un servicio telefónico post-venta, el coste debe ser el de una «tarifa básica», aunque ciertamente esta norma no define el concepto de tarifa básica.

En respuesta a la consulta, el Tribunal de Justicia europeo dictaminó que, efectivamente, la tarifa básica equivale al precio de una llamada estándar y que, por tanto, en ningún caso puede exceder del coste de la llamada a una línea estándar.

El Abogado General del caso había defendido durante el juicio esta definición puesto que las tarifas especiales pueden disuadir al consumidor de ejercer sus derechos y se le penaliza por utilizar un servicio que ya aparecía incluido en su contrato con la empresa proveedora.

\section{Tribunal de Justicia: nueva sentencia sobre los préstamos hipotecarios} en España que establece mayores plazos y la revisión de oficio por parte de los jueces

El Tribunal de Justicia de la UE emitió en enero una nueva sentencia sobre los préstamos hipotecarios españoles, esta vez en respuesta a la consulta de un juzgado de Santander.

En esta ocasión, la Corte de Luxemburgo decidió que es necesario más tiempo para que los jueces puedan dictaminar el carácter abusivo de una cláusula hipotecaria y reclamó además que los jueces que aborden un asunto hipotecario puedan examinar el carácter abusivo de todas las cláusulas del contrato y no únicamente de aquellas que están en cuestión.

El Tribunal, como ya había hecho anteriormente en una sentencia similar, declaraba que el plazo de un mes que se da para declarar nulas las cláusulas abusivas de un contrato es contrario al Derecho de la Unión pues «este plazo, no permite garantizar que los consumidores puedan aprovechar plenamente este tiempo y, en consecuencia, ejercitar efectivamente sus derechos».

El Tribunal establecía así mismo que, aunque se haya producido un examen previo de oficio por parte de un juez de primera instancia, «el derecho de la Unión impone a un juez nacional la obligación de apreciar el eventual carácter abusivo de las demás cláusulas de dicho contrato» para determinar si en éstas existe un desequilibrio importante entre los derechos y obligaciones de las partes del contrato en detrimento del consumidor.

En el caso concreto de las cláusulas de vencimiento anticipado, el juez debería examinar si las condiciones son equilibradas y si la entidad estaría 
capacitada para activarla cuando la situación de impago revista una gravedad suficiente en relación con la duración y la cuantía del préstamo.

\section{Competencia: multa a seis fabricantes de piezas de climatización para automóviles}

En marzo, la Comisión Europea impuso una sanción de 155 millones de euros a seis compañías dedicadas a la fabricación de piezas de control de climatización y de refrigeración de motores de vehículos, por pactar precios y compartir información sensible.

Las empresas japonesas Calsonic, Denso, Sanden y Panasonic, la alemana Behr y la francesa Valeo, articularon acuerdos ilegales a través de cuatro cárteles distintos.

Mantenían reuniones en Europa y Japón, así como contactos telefónicos y por correo electrónico para fijar condiciones de venta favorables a sus intereses. «Aunque no puedas ver los componentes de climatización y refrigeración de tu vehículo, sufres los efectos [del cartel]. En este caso puedes haberlo sentido en tu cartera aunque las temperaturas estuvieran correctamente reguladas», afirmo entonces la comisaria de Competencia, Margrethe Vestager.

Panasonic fue la única de las seis compañías que no tuvo que abonar ninguna multa dado que fue la que desveló la trama Las mayores sanciones fueron impuestas a la germana Behr y a la japonesa Sanden, que tendrán que pagar en torno a 65 millones de euros, mientras que la francesa Valeo deberá pagar 27 millones.

\section{Comisión: multa a Facebook}

La Comisión Europea impuso el 18 de mayo una multa de 110 millones de euros a Facebook por haber proporcionado datos «incorrectos o engañosos» sobre la compra de la empresa de mensajería instantánea WhatsApp, una operación a la que Bruselas había dado su visto bueno en 2014 y que, en todo caso, no se verá afectada por esta sanción.

«Es una multa proporcionada y disuasoria», explicó la comisaria Vestager, en una declaración en la que subrayó que este tipo de decisiones del ejecutivo comunitario son una «señal fuerte» a las compañías de que deben «respetar las reglas» de la Unión Europea y proporcionar «información exacta» cuando son investigadas.

La Comisión cree probado que la empresa norteamericana ocultó en el momento de notificar la compra en 2014 que contaba ya con los avances 
técnicos necesarios para vincular de manera fiable y automática los datos de los clientes de ambas redes sociales, pese a que en la información remitida a Bruselas y en un cuestionario posterior dijo lo contrario.

La falsedad se demostró ya en agosto de 2016, cuando WhatsApp anunció una actualización de los términos y condiciones de su servicio que incluía la posibilidad de que los teléfonos asociados a la aplicación se vincularan con los perfiles correspondientes en Facebook.

En este contexto, la Comisión abrió formalmente un expediente a Facebook con el envío de un pliego de cargos en diciembre de 2016, una investigación que concluía cinco meses después.

Con todo, Bruselas aclaró que la sanción no afecta a la operación de compra, ya que ésta fue aprobada teniendo en cuenta «una serie de elementos distintos» a la capacidad para vincular los perfiles de los usuarios de las dos redes sociales.

\section{Sobre el autor}

Beatriz Iñarritu Ibarreche es Doctora por la Universidad de Deusto y Licenciada en Ciencias Económicas y Empresariales por la Universidad Comercial de Deusto. Su tesis, «Sistemas de Gobernanza Económica Europea: propuesta de Análisis y Medición», la realizó en el marco del programa de Estudios Internacionales e Interculturales de la Universidad de Deusto. Desde 1988, ha impartido docencia sobre Economía de la UE, en las Licenciaturas de Ciencias Económicas y Empresariales y Derecho de la UD, en la Escuela Universitaria de la Cámara de Comercio de Bilbao, y en los Institutos de Ocio y de Estudios Europeos de la UD. Actualmente, imparte docencia en el Departamento de Economía de Deusto Business School de la UD. Socia de Estrategias Empresariales Europeas, E-3, en la que dirige y desarrolla diferentes proyectos de consultoría en el campo de la internacionalización empresarial y de la UE. Ha sido profesora en el Diploma sobre Derecho Comunitario de la Universidad Iberoamericana de México en colaboración con la UD, impartiendo el módulo sobre «Mercado Interior Europeo e implantación del Euro» en México DF. Es ponente habitual en jornadas organizadas por entidades y organismos empresariales que contribuyen al mayor conocimiento de las diferentes cuestiones relacionadas con la UE y la internacionalización empresarial. Ha participado en un Equipo de Investigación de la UD en el proyecto «Instrumentos Innovadores de Gobernanza de la Unión Europea. Impacto en la gestión pública y en la competitividad regional».

Es autora de la sección «Crónica Comunitaria: la actualidad institucional y económica de España en el marco de la UE» en «Cuadernos Eu- 
ropeos de Deusto», revista editada por la UD. Es coautora de las publicaciones anuales «Guía de la Movilidad en la UE» y «Apuntes sobre la UE y Bizkaia» editadas por la Diputación Foral de Bizkaia. Ha sido coautora del Caso de Internacionalización publicado por el ICEX: «Inauxa, una Pyme en el Mercado Mundial de Automoción».

\section{About the author}

Beatriz Iñarritu Ibarreche is a Doctor of the University of Deusto and holds a degree in Economics and Business Studies from the Commercial University of Deusto. Her thesis, «Systems of European Economic Governance: Proposal for Analysis and Measurement», was carried out within the framework of the program of International and Intercultural Studies of the University of Deusto. Since 1988, she has lectured on EU Economics, in the Bachelor's of Economics and Business Studies and Law at the UD, at the University School of the Chamber of Commerce of Bilbao, and at the Institutes of Leisure and European Studies of the UD. Currently she teaches in the Department of Economics of Deusto Business School of the UD. Partner of European Business Strategies, E-3, in which she directs and develops different consulting projects in the field of business and EU internationalization. She has taught in the Diploma on Community Law of the Universidad Iberoamericana de México in collaboration with the UD, giving the module on «European Internal Market and implementation of the Euro» in Mexico DF. She is a regular speaker at conferences organized by business entities and organizations that contribute to a better understanding of the different issues related to the EU and business internationalization. She has participated in a Research Team of the UD in the project «Innovative Instruments of Governance of the European Union. Impact on public management and regional competitiveness ».

She is the author of the section «Community Chronicle: the institutional and economic news of Spain within the framework of the EU» in «Cuadernos Europeos de Deusto», a magazine edited by the UD. She is co-author of the annual publications «Guide to Mobility in the EU» and «Notes on the EU and Bizkaia» edited by the Provincial Council of Bizkaia. She has co-authored the Internationalization Case published by the ICEX: «Inauxa, a SME in the World Automotive Market». 


\section{Derechos de autor}

Los derechos de autor (para la distribución, comunicación pública, reproducción e inclusión en bases de datos de indexación y repositorios institucionales) de esta publicación (Cuadernos Europeos de Deusto, CED) pertenecen a la editorial Universidad de Deusto. El acceso al contenido digital de cualquier número de Cuadernos Europeos de Deusto es gratuito inmediatamente después de su publicación. Los trabajos podrán leerse, descargarse, copiar y difundir en cualquier medio sin fines comerciales y según lo previsto por la ley; sin la previa autorización de la Editorial (Universidad de Deusto) o el autor. Así mismo, los trabajos editados en CED pueden ser publicados con posterioridad en otros medios o revistas, siempre que el autor indique con claridad y en la primera nota a pie de página que el trabajo se publicó por primera vez en $C E D$, con indicación del número, año, páginas y DOI (si procede). Cualquier otro uso de su contenido en cualquier medio o formato, ahora conocido o desarrollado en el futuro, requiere el permiso previo por escrito del titular de los derechos de autor.

\section{Copyright}

Copyright (for distribution, public communication, reproduction and inclusion in indexation databases and institutional repositories) of this publication (Cuadernos Europeos de Deusto, CED) belongs to the publisher University of Deusto. Access to the digital content of any Issue of Cuadernos Europeos de Deusto is free upon its publication. The content can be read, downloaded, copied, and distributed freely in any medium only for non-commercial purposes and in accordance with any applicable copyright legislation, without prior permission from the copyright holder (University of Deusto) or the author. Thus, the content of $C E D$ can be subsequently published in other media or journals, as long as the author clearly indicates in the first footnote that the work was published in $C E D$ for the first time, indicating the Issue number, year, pages, and DOI (if applicable). Any other use of its content in any medium or format, now known or developed in the future, requires prior written permission of the copyright holder. 